\title{
EUS-guided drainage with LAMS to treat a refractory micro-fistula after sleeve gastrectomy: Widen the fistula if you cannot seal it $\square$
}

A 26-year-old female with a history of sleeve gastrectomy presented with a leak and underwent surgical drainage. She had recurrent sepsis 3 days later due to a perigastric abscess.

An esophageal stent $(23 \mathrm{~mm} \times 15 \mathrm{~cm})$ was deployed [1-3] and sutured to the wall.

The abscess was aspirated percutaneously. A percutaneous drain could not be placed due to a difficult location. She was discharged.

Three weeks later, the patient had a recurrent abscess ( $\mathbf{F i g} \mathbf{1} \mathbf{1}$ ). The stent was removed and no patent orifice was identified. Pneumatic dilation of narrowing at the incisura angularis [1-3] was performed (30-mm balloon, PSI 15). Endoscopic ultrasound (EUS)-guided drainage using a double pigtail stent was performed ( $>$ Fig. 2 ) and the patient was discharged.

After confirming resolution of the abscess the stent was removed, pneumatic dilation was repeated, and the site of entry was sutured. An upper gastrointestinal series showed no leakage.

Two months later, the patient had a recurrent abscess. Pneumatic dilation was repeated, followed by EUS-guided drainage using a hot LAMS $(1.5 \mathrm{~cm})$ ( $\mathbf{F i g} .3$ ). The abscess was lavaged. Two double pigtail stents were deployed inside a lumen apposing metal stent (LAMS). A nasoduodenal feeding tube was placed. The patient was discharged.

After confirming resolution of the abscess, the stents and the feeding tube were removed. A septum separated the cavity from the gastric lumen ( $\triangleright$ Fig.4). Septotomy [4] and pneumatic dilation were performed (\$ Fig.5). The patient was discharged.

Endoscopy 3 months later showed epithelialization of the cavity ( $>$ Fig. $\mathbf{6}$ ). The patient has been asymptomatic for the last 4.5 months.

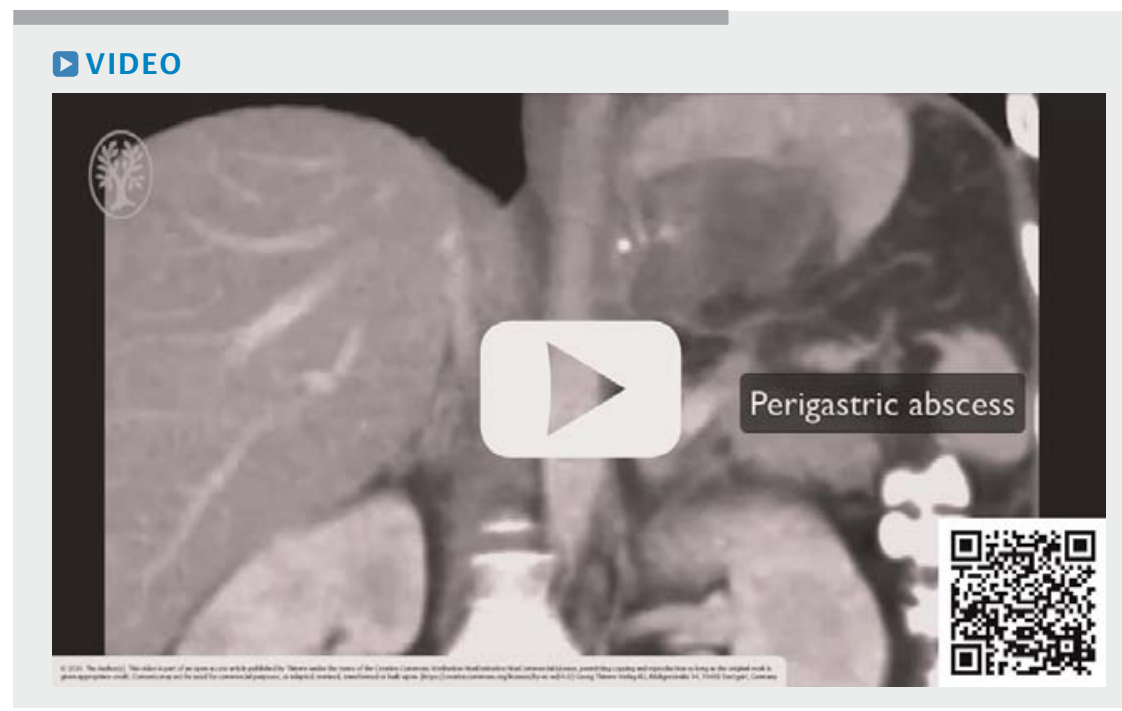

- Video 1 Endoscopic management of a refractory leak after sleeve gastrectomy.

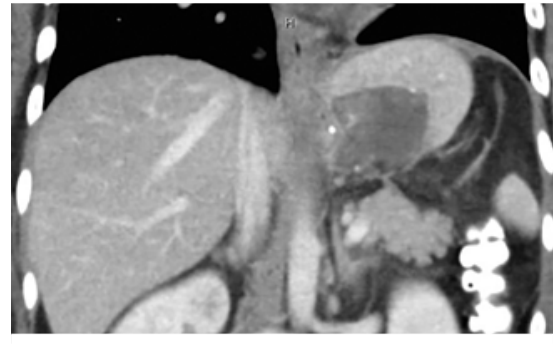

- Fig. 1 CT image of the perigastric abscess.

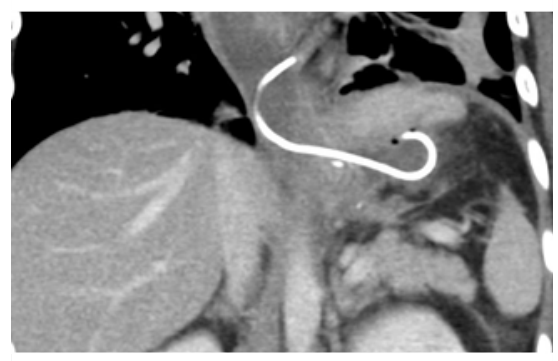

- Fig. 2 CT after EUS-guided drainage using a double pigtail stent.

In conclusion, EUS-guided drainage with a LAMS can be used to widen a refractory micro-fistula after sleeve gastrectomy to allow septotomy.

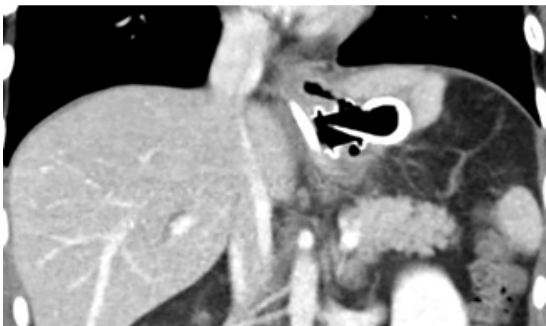

- Fig. 3 CT after EUS-guided drainage using LAMS.

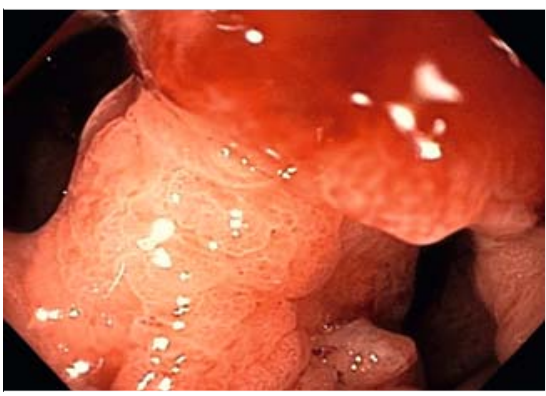

- Fig. 4 Septum separating the cavity from the gastric lumen. 


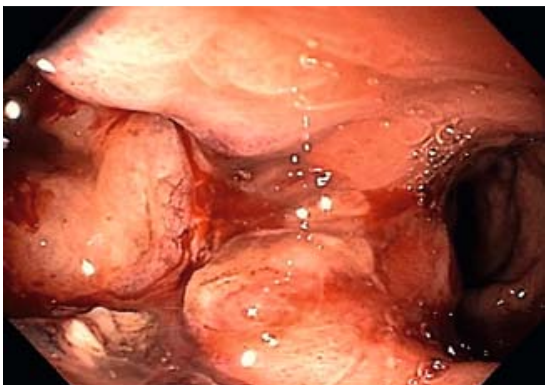

Fig. 5 Endoscopic image after septotomy.

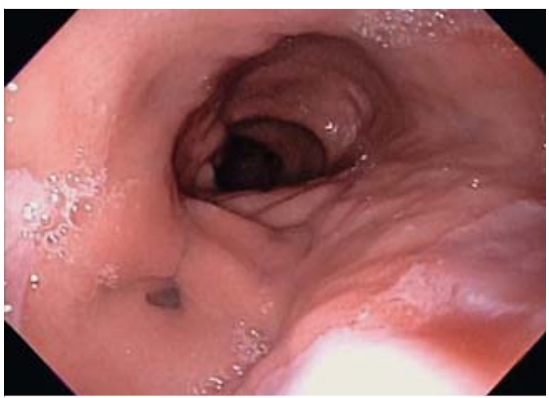

- Fig. 6 Endoscopic image showing collapse and epithelialization of the cavity.

\section{Competing interests}

The authors declare that they have no conflict of interest.e

The author

\section{Michael Lajin}

Sharp Grossmont Hospital, La Mesa, California, United States

\section{Corresponding author}

\section{Michael Lajin}

8860 Center Drive Suite 330, La Mesa,

California 91942, USA

Fax: +1-619-460-5148

mlajin@yahoo.com

\section{References}

[1] Rosenthal R], Panel IS. International Sleeve Gastrectomy Expert Panel Consensus Statement: best practice guidelines based on experience of $>12,000$ cases. Surg Obes Rel Dis 2012; 8: 8-19
[2] Vargas EJ, Dayyeh BK. Keep calm under pressure: a paradigm shift in managing postsurgical leaks. Gastrointest Endosc 2018; 87: 438-441

[3] Kumbhari V, Dayyeh BK. Keeping the fistula open: paradigm shift in the management of leaks after bariatric surgery? Endoscopy 2016; 48: 789-791

[4] Diaz R, Welsh LK, Perez JE et al. Endoscopic septotomy as a treatment for leaks after sleeve gastrectomy: Meeting presentations: Digestive Disease Week 2019. Endoscopy international open 2020; 8: E70-E75

\section{Bibliography}

Endoscopy International Open 2021; 09: E419E420

DOI 10.1055/a-1326-1677

ISSN 2364-3722

(C) 2021. The Author(s).

This is an open access article published by Thieme under the terms of the Creative Commons Attribution-NonDerivativeNonCommercial License, permitting copying and reproduction so long as the original work is given appropriate credit. Contents may not be used for commecial purposes, or adapted, remixed, transformed or built upon. (https:// creativecommons.org/licenses/by-nc-nd/4.0/)

Georg Thieme Verlag KG, Rüdigerstraße 14, 70469 Stuttgart, Germany

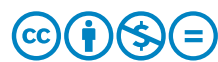

